\title{
A CONSTITUIÇÃO DE UM TERRITÓRIO IDENTITÁRIO PELA GARANTIA DOS DIREITOS FUNDIÁRIOS: O SÍTIO HISTÓRICO E PATRIMÔNIO CULTURAL KALUNGA
}

\author{
The constitution of a identity territory for warranty of land rights: \\ The Historic and Cultural Site Kalunga
}

\author{
Luana Nunes Martins de Lima \\ Aluna do Mestrado em Geografia \\ Universidade Federal de Goiás, Goiânia, Goiás, Brasil \\ luanunes_7@hotmail.com
}

Artigo recebido em 05/02/2013 e aceito para publicação em 30/04/2013

RESUMO: O artigo trata sobre a constituição do Sítio Histórico e Cultural Kalunga, situado no Norte Goiano, tecendo considerações que abrangem as comunidades nele distribuídas, a forma de ocupação no Cerrado goiano e o reconhecimento oficial de seu território. Apresenta uma discussão sobre como os discursos de autoafirmação identitária e a patrimonialização de territórios quilombolas modificam as estratégias reprodutivas desses grupos. Esse processo, porém, só ocorre pela interferência externa que atua na conscientização dessas comunidades com relação aos seus direitos constitucionais. Diante da necessidade de autoatribuição, o discurso da identidade ressignifica o sentido da luta dessas comunidades: o direito a terra. Por fim, destaca-se a problemática com relação à titulação comunitária da terra. Essas questões são debatidas mediante uma revisão bibliográfica que permeou a temática, observações e entrevistas realizadas em pesquisa de campo. Preliminarmente, há algumas conclusões que apontam para a necessidade de repensar as políticas que priorizam a preservação cultural direcionadas às comunidades quilombolas, em detrimento de suas reais demandas.

Palavras-chave: Comunidades Quilombolas, Território Kalunga, identidade, direito fundiário

ABSTRACT: The article discusses the constitution of Historic and Cultural Site Kalunga, situated in the north of Goiás, making considerations about the communities it distributed in, the form of occupation in Cerrado of Goiás and the official recognition of its territory. Presents a discussion about how the discourses of identity self-assertion and the patrimonialization of quilombolas territory modify the reproductive strategies of these groups. This process, however, only occurs by external interference that works in raising awareness of these communities in relation to their constitutional rights. Before the need of self-assertion, the discourse of identity resignify the meaning of these communities struggle: the right to land. Finally, it detach the problem regarding community title of land property. These issues are discussed through a literature review that permeated the theme, observations and interviews made on the spot. Preliminarily, there are some conclusions that point to the need to rethink the policies that prioritize the cultural preservation directed to the quilombolas communities, rather than their actual demands.

Key-word: Quilombolas Communities, Kalunga Territory, Identity, Land Rights 


\section{INTRODUÇÃO}

As comunidades denominadas quilombolas são grupos sociais cuja identidade étnica e cultural os distinguem no conjunto da sociedade. Tais comunidades desenvolveram ao longo da formação histórica brasileira características próprias de ocupação da terra, organização social, produtiva e religiosa. Por mais de dois séculos essas comunidades formadas por antigos escravos, negros alforriados, constituídas em quilombos buscam por seus direitos e pela garantia de seus territórios.

Com a inclusão do Artigo 68 no Ato das Disposições Constitucionais Transitórias da Constituição Federal (ADCT) de 1988, que prevê o reconhecimento da propriedade das terras dos remanescentes de quilombos, esses grupos foram finalmente reconhecidos oficialmente pelo Estado e passaram a buscar de maneira mais efetiva seus direitos.

O reconhecimento e a titulação das terras ocupadas por comunidades remanescentes de quilombos têm como objetivo garantir a preservação de valores culturais e históricos relativos à contribuição do negro no processo de formação do povo brasileiro. Entretanto, diante do critério de autoatribuição quanto a ser quilombola, a luta pela terra assumiu uma nova dimensão e direcionamento, uma vez que a reivindicação deixou de ser apenas de camponeses negros e passou a ser de remanescentes quilombolas. Essa mudança exigiu amplas iniciativas dos órgãos responsáveis e dos próprios membros das comunidades, que passam por um processo de adaptação e reelaboração histórica e identitária, com a finalidade exclusiva de garantia de posse do território.

Por meio desse artigo pretende-se problematizar a constituição do Sítio Histórico e Cultural Kalunga a partir das mudanças nas estratégias de reprodução das comunidades frente às políticas e discursos de autoafirmação étnica. Além disso, têm-se a hipótese de que a propriedade da terra é o principal motivo que os leva a assumir uma identidade cultural específica, e que essa identidade, por vezes, tem sido objeto de manipulação.

Para tanto, o seu conteúdo foi organizado em três partes claramente distintas, porém complementares. A primeira trata de uma forma geral sobre o sítio
Kalunga, as comunidades nele distribuídas, a forma de ocupação no Cerrado goiano e o reconhecimento oficial de seu território. A segunda apresenta uma discussão sobre como discursos que versam sobre a importância da autoafirmação identitária quilombola conduz a certo tipo de essencialismo; e como a patrimonialização de territórios quilombolas modificam as estratégias reprodutivas desses grupos. A terceira destaca a questão da titulação comunitária da terra pela preservação histórica e cultural, como geradora de imposições que impedem os Kalunga de disporem plenamente do direito de propriedade.

\section{TERRITÓRIO, IDENTIDADE E A LUTA PELA TERRA}

De acordo com o Decreto 4.887 de 2003, a Fundação Cultural Palmares (FCP) é responsável pela certificação e o Instituto Nacional de Colonização e Reforma Agrária (INCRA) é responsável pela emissão dos títulos definitivos das terras de remanescentes de quilombos. Segundo os dados da Fundação Cultural Palmares (2008), o Governo Federal, entre 1995 a 2008, já havia identificado 3.524 comunidades distribuídas em todo o país, com 1.087 certificações emitidas, beneficiando 1.305 comunidades.

Dentre essas comunidades encontram-se, na mesorregião Norte Goiano, nos municípios de Cavalcante, Monte Alegre e Teresina de Goiás, os Kalunga. Em termos numéricos e históricos está entre as maiores do país, ocupando uma área de 253,2 mil hectares do Cerrado, com uma população estimada de 3.752 habitantes, de acordo com os dados de 2004 do "Perfil das Comunidades Quilombolas: Alcântara, Ivapurunduva e Kalunga". Essa população formou-se de quilombolas, índios, posseiros e proprietários de terras que adentravam a região.

O Norte Goiano não se inseriu efetivamente no processo de expansão e modernização da fronteira agropecuária, que em parte foi impedida pelos limites estabelecido pelo Parque Nacional da Chapada dos Veadeiros e pelo predomínio das formas serranas, com relevo formado por vales e chapadas entremeados por rios encaixados. De acordo com Almeida (2005), essa área ainda mantém boa parte do Cerrado conservado, destacando-se pelas variações de Cerrado de altitude, 
como formações campestres e formações savânicas. Há também a ocorrência de veredas, que são substituídas por matas ciliares, na medida em que a drenagem se define. Nas elevações em direção ao Vale do Rio Paranã, há o domínio de formações florestais, onde a terra é considerada propícia para o plantio de roçados.

As comunidades Kalunga situam-se entre os Vãos da Serra Geral, parte ocupada pelo vale do Rio Paranã e seus afluentes. As serras e morros dividem as comunidades em alguns núcleos principais nos três municípios: o Vão do Moleque, o Vão das Almas, o Vão da Contenda, o Ribeirão dos Bois e o Engenho II (MARINHO, 2008).

A relação dessas comunidades com o Cerrado é significativa e se expressa no uso dos recursos naturais: nas áreas de roçado, nos quintais, no cultivo de plantas medicinais, no conhecimento das espécies, entre outros. Suas formas de apropriação pouco alteraram o Cerrado enquanto ambiente natural.

Para Almeida (2010, p.43), os Kalunga, que ela inclui no grupo dos cerradeiros, "reconhecem a herança cultural e o local de vivências com suas características naturais, como definidores de seu grupo social e de sua identidade territorial". Assim, a diversidade do Cerrado permite afirmar que:

territórios identitários estão contidos no território do Cerrado. Como territórios identitários eles se caracterizam pelo papel primordial da vivência e pelo marco natural, o Cerrado; eles seriam tanto espaços de sociabilidade comunitária como refúgios frente às agressões externas de qualquer tipo. (ALMEIDA, 2005, p. 338)

Haesbaert (2007), nesse sentido, defende que as bases que dão mais consistência e eficácia na construção da identidade de um grupo são as referências espaciais materiais (no presente ou no passado). Ele verifica claramente o elo entre espaço, política e cultura, afirmando que a identidade territorial só se efetiva a partir da referência a um recorte espacial, no qual o grupo se identifique e aja politicamente, ou seja, acionem "identidades territoriais de acordo com as estratégias políticas em jogo" (HAESBAERT, 2007, p. 45).
Segundo Baiocchi (2006), mesmo com a primeira titulação coletiva de propriedade das terras ocorrida em 1985, os anos de 1978 a 1990 foram fortemente marcados pela entrada de empresários rurais, fazendeiros e grileiros no território Kalunga. $\mathrm{Na}$ verdade, esse primeiro registro de terras impulsionou ainda mais as invasões e pressões sobre a população, criando intensos conflitos e despejos coletivos. Isso fez com que a população se posicionasse por meio da Associação Povo da Terra Kalunga e de seus vereadores. Assim, iniciou-se uma mudança na forma de a comunidade organizar-se politicamente, bem como o modo e os interesses de se reunirem e de elegerem seus representantes.

Em 1991 o território Kalunga foi reconhecido pela Lei Complementar do Estado de Goiás, número 11.409-91, que em seu texto delimita a área do sítio histórico, prevê a exclusividade da propriedade das terras aos seus habitantes, bem como a desapropriação e a titulação em favor da comunidade. Essa foi subsidiada por estudos e pela construção de um mapa da região dos Kalunga feito pela equipe do Projeto Kalunga Povo da Terra da Universidade Federal de Goiás e adotado pelo extinto IDAGO (Instituto de Desenvolvimento Agrário de Goiás), que sancionou o direito a primeira titulação de terras aos Kalunga. Foi posteriormente ratificada pela Lei Complementar 19/1995 (BAIOCCHI, 2006).

Atualmente, a norma federal que regulamenta o "procedimento para identificação, reconhecimento, delimitação, demarcação, desintrusão, titulação e registro das terras das comunidades quilombola" é o Decreto 4.887, de 20 de novembro de 2003, segundo o qual

consideram-se os remanescentes das comunidades dos quilombos, os grupos étnico-raciais, segundo critérios de autoatribuição, com trajetória histórica própria, dotados de relações terrritoriais especificas, com presunção de ancestralidade negra, relacionada com a resistência à opressão histórica sofrida (Fundação Cultural Palmares, 2008). 
Para Arruti (2006) a utilização do termo "remanescentes de quilombos" é uma forma de tornar essas comunidades negras nomeáveis, classificando-as, e admitindo nelas a presença do estado de negro/escravo, com fim de dar a elas visibilidade. O termo, assim, assume uma dimensão político-ideológica, que se agrega à questão da territorialidade, outro elemento de ordem identitária. O termo de quilombos contemporâneos adotado pela Associação Brasileira de Antropologia (1994) não se refere a resíduos ou resquícios arqueológicos de ocupação temporal ou de comprovação biológica. Também não se trata de grupos isolados ou de uma população estritamente homogênea. Não significa que foram constituídos a partir de movimentos insurrecionais ou rebelados, mas, sobretudo, consistem em grupos que desenvolveram práticas de resistência na manutenção e reprodução de seus modos de vidas característicos num determinado lugar.

Com o requisito da autoatribuição, as interferências externas se tornaram fundamentais na construção da identidade territorial dos Kalunga. De acordo com Marinho (2008), a partir do reconhecimento que eles receberam, muitas políticas passaram a ser implementadas nas comunidades, o que influenciou a organização social, e consequentemente, a dinâmica cultural e identitária dessas comunidades.

Para a autora, foi evidenciado que o interesse e o esforço coletivo dos Kalunga pelo reconhecimento oficial são motivados pela intenção de resolver os conflitos fundiários, nos quais as comunidades sempre estiveram envolvidas, e não pela intenção de se afirmarem como continuidade histórica e cultural, como é interpretado por alguns o termo "remanescente de quilombo". Até pouco tempo atrás havia uma negação dessas comunidades de seu passado e até mesmo uma negação quanto ao ser Kalunga, pela noção colonial que esse termo assumia; uma noção que ignorava os outros processos que o conceito de quilombos contemporâneos assume. A autora afirma que

\section{[...] suas demandas de reconhecimento muitas} vezes não estão carregadas de uma temática social ou não se tem consciência por parte do grupo do que seriam tais demandas, especialmente às relacionadas ao movimento negro, que lutam pelo fim do racismo. As demandas agrárias também são desvinculadas de movimentos pró-reforma agrária, na realidade, em muitos casos, a luta pelo território negro não passa pelo crivo de um ideal reformista em nenhum dos casos que eu estudei muito menos no território Kalunga. Por outro lado, ao perceber a possibilidade de reconhecimento as comunidades quilombolas passaram a se identificar cada vez mais pelo icone quilombola, por uma identidade cultural especifica. (MARINHO, 2008, p.60)

A negação da origem quilombola e o interesse por se distanciar da matriz colonial se tornou, na atualidade, uma reivindicação do estigma 'ser quilombola', 'ser Kalunga', como forma de institucionalizar o grupo e como estratégia de preservação por meio da titulação do território.

Com relação a esse interesse pela identificação de quilombola, Almeida (2010) acrescenta que a presença da Fundação Cultural Palmares e das ações das políticas governamentais em torno dessa questão consolidaram a autoidentificação dos Kalunga como quilombolas e a procura por dar visibilidade de seus saberes tradicionais. Com base nisso, ela afirma que "a representação que as pessoas têm da sua posição no espaço social e de sua relação com outros atores que ocupam a mesma posição ou posições diferenciadas no mesmo espaço é fundamental para definir a identidade" (ALMEIDA, 2010, p. 121).

A autora concorda com Marinho (2008), ao enfatizar que a noção de "patrimônio" para os Kalunga remete à propriedade das terras. $\mathrm{O}$ sentido da terra tem uma perspectiva material de sobrevivência, porque da terra retiram seu sustento. Disso resultam as persistências das comunidades junto aos órgãos governamentais, os embates contra as invasões de garimpeiros, fazendeiros, grileiros, entre outros.

Alguns moradores das comunidades Diadema e Ribeirão demonstraram falta de conhecimento ou compreensão do sentido da designação dada ao seu próprio território (Sítio Histórico e Patrimônio Cultural Kalunga), confirmando que consideram, de fato, apenas a questão fundiária. Nesse sentido, a fala de alguns moradores manifesta certa consciência e resistência quando seu território é ameaçado, como corrobora o trecho: 
Aqui tem um negócio que esse povo tava falando que há muitos anos que eles vai por uma barragem aqui, nesse Funil ai. Essa barragem num é de agora não. Ai uns fala que vai por essa barragem, outros fala que num faz, outros fala que faz, outros fala que pra fazer essa barragem o povo tem que assinar, se não, num faz. Outros fala que não, mesmo que num assinar, faz. Esse povo aqui é grande, o nome desse povo aqui tá longe. Como é que vai fazer essa barragem com esse povo tudo no Cerrado aí? (Morador de Diadema, 48 anos - Entrevista realizada em 03/05/2011).

Diante disso, uma pergunta se coloca: se a questão primordial no reconhecimento é a garantia da propriedade da terra (e esta já está assegurada por lei), por que surge simultaneamente uma busca enfática pela visibilidade cultural, dos saberes, das manifestações culturais, das "raízes", que, por vezes, interfere na forma de vida e nas estratégias de reprodução dessas comunidades?

\section{DAPATRIMONIALIZAÇÃO DOSÍTIO KALUNGA AO ESSENCIALISMO}

Para pensar essa questão, deve-se levar em conta o fenômeno de etnogênese, dentro do qual, ocorre, por meio da tomada de consciência, a emergência de novos sujeitos políticos capazes de organizarem-se em torno de um projeto político e social comum (ARAÚJO; NAZARENO, 2011).

Nesse processo (etnogênese), os grupos se reforçam tentando voltar e reconstituir o que foi ignorado ou subalternizado. É impossível recriar o original, o que se faz é reconstituir fragmentos do que foi apreendido. Assim, busca-se reforçar padrões e complexos tradicionais para garantir benefícios políticos e, sobretudo, autonomia territorial. Determinados traços culturais que eram negados, hoje são retomados porque garantem certa visibilidade e funcionalidade frente a outras forças sociais. O que foi marginalizado, negado ou simplesmente desconhecido, passa a ser aceito e usado como estratégia de sobrevivência. Esse processo, geralmente, decorre de uma interme- diação; que no caso das comunidades Kalunga, partiu da Fundação Cultural Palmares.

A abrangência das interpretações que o termo "remanescente de quilombos" assumiu gera intensos debates e pressões da sociedade sobre as comunidades Kalunga, que passam a ser vistas como um tipo de "espetáculo". Muitos visitam as comunidades motivados pelo conceito de quilombos da época da escravidão, ansiando encontrar grupos vivendo em relações arcaicas de produção e reprodução social, misticismos e práticas associadas a símbolos de uma identidade africana. Em outras palavras, procuram a "África" no Cerrado. Mari Baiocchi, a antropóloga que coordenou o projeto "Kalunga: Povo da Terra" (1981 - 2004), que fundamentou a lei complementar de número 11.409-91, compartilha desta visão ao afirmar que: "Os Kalunga remetem-nos à África, quando o isolamento geográfico-cultural possibilita a reificação das tradições e costumes" (BAIOCCHI, 2006, p.14); e ainda sobre as manifestações culturais dos Kalunga ela enfatiza: "festeja-se Santo Católico em Espaço Africano" (BAIOCCHI, 2006, p.41).

É importante também considerar como as comunidades Kalunga passaram a ser o alvo de numerosas pesquisas, reportagens, exposições fotográficas, especulações turísticas, entre outros, principalmente após o reconhecimento como remanescentes de quilombos.

A crítica de Arruti (2006) a esse tipo de pressão deve-se ao fato de que, em muitos casos, força-se uma definição pragmática de identidade, na qual o discurso de manutenção da cultura original garanta um status de legitimidade e os traços culturais realcem a etnicidade do grupo, objetivando adequar o passado ao presente. Ou seja, quanto mais semelhanças relacionadas ao passado de quilombo os remanescentes possuírem, mais legitimidade para garantir os benefícios previstos no artigo 68 do ADCT eles terão. Sobre isso, uma moradora fez uma declaração que confirma como essa pressão, mencionada por Arruti (2006), torna-se desfavorável para as comunidades: 
E agora eles querem que a gente fica ali naquilo que era. Tem uns que vem e que fala que diz que num era nem pra ter mudado as nossas casa não, que era pra ser de palha. [...] Pois é, era pra ser de palha! O tempo todo, aquela vidinha assim ó, que num era pra crescer nada. Não! Isso aí num tem jeito não. (Moradora de Diadema, 54 anos - Entrevista realizada em 04/05/2011)

A emergência desses movimentos identitários resulta em um tipo de essencialismo, que exige uma especificidade performática entre os Kalunga. Ocorre uma supervalorização do local por causa de suas especificidades para contrapor a homogeneização que a globalização institui. Sobre isso Featherstone (1997, p. 132) afirma que a compressão global e a intensidade dos fluxos globais geram reações nacionalistas énticas e fundamentalistas, ao passo que acarreta uma forte afirmação das culturas locais; o que "poderia assumir a forma de reviver, simular ou inventar novas cerimônias e tradições locais".

O essencialismo estratégico, termo cunhado por Gayatri Spivak e também utilizado por Bhabha (1998), se refere a uma prática baseada em uma naturalização de identidades e culturas, com essência imutável, como meio de obtenção de direitos. Para o autor, essa forma de essencialismo é evidenciada principalmente diante da ameaça do hibridismo e da diluição cultural de alguns povos ante a globalização. No caso de comunidades remanescentes de quilombos, como os Kalunga, o hibridismo ou a diluição cultural são percebidos principalmente nas migrações constantes para a cidade, por meio das quais se perde o vínculo com as tradições e os modos de vida da comunidade. $\mathrm{O}$ essencialismo se expressa na tentativa de alcançar determinados objetivos, como a visibilidade dos órgãos estatais e da sociedade civil em geral, visando a garantia do direito a terra.

Os representantes e alguns membros da Associação da Comunidade Quilombola de Cavalcante participam de seminários regionais e nacionais sobre a temática dos remanescentes de quilombo e movimento negro. Informam-se sobre discussões que ocorrem nesse campo, buscando coadunar-se com lideranças de outras comunidades, como uma forma de garantir maior acesso a legisladores e políticos. Nas comunidades, a Associação age no sentido de conscientizar a população sobre os assuntos relativos ao reconhecimento e titulação da terra, e também na obtenção de recursos e projetos junto às Universidades, Organizações não governamentais e órgãos estatais. Além disso, os líderes comunitários se esforçam para que as representações e rituais Kalunga sejam perpetuados nas próximas gerações, o que os levam a apresentar as tradições o mais próximo possível da forma como eram realizadas no passado, na tentativa de dar visibilidade às mesmas. Este aspecto é assinalado por Bhabha (1998, p.76),

[...] a questão da identificação nunca é a afirmação de uma identidade pré-dada, nunca uma profecia autocumpridora - é sempre a produção de uma imagem de identidade e a transformação do sujeito ao assumir aquela imagem. A demanda da identificação - isto é, ser para um Outro - implica a representação do sujeito na ordem diferenciadora da alteridade.

Os critérios patrimoniais são extremamente funcionais para definirem territórios locais fortemente legítimos. Bourdin (2001) levanta um debate político e científico sobre o lugar da dimensão local nas sociedades contemporâneas, mostrando como o local se torna o lugar da resistência à mundialização. Para ele, há uma tendência de reprodução de um discurso conservador que valoriza a família, a comunidade religiosa, cultural ou étnica, a vizinhança, entre outros grupos locais. Essa visão de sociedade coloca de um lado o indivíduo, que se afirma cada vez mais, mesmo onde essa noção de indivíduo nem existia; e de outro, grupos marcados pela singularidade de valores, afetividade, modos de vida, memória, ou seja, enraizados ao lugar.

$\mathrm{O}$ autor afirma que as identidades das comunidades locais, construídas pela ação coletiva e mantidas pela memória coletiva são formas de defesa e preservação em relação à desordem global. O identitarismo, as ideologias comunitárias, do patrimônio e do cotidiano são movimentos de ideologias que favorecem a localização e os recortes do social em função das vantagens ou da proteção que eles podem trazer. 
Em crítica à reivindicação tão latente de uma identidade local, à busca por raízes e ao interesse pelo patrimônio que culminam na supervalorização do local em detrimento da globalização, Bourdin (2001, p.203-4) apresenta três formas de afirmação do local. A primeira é a que faz "do lugar a base do interesse comum a todos os interesses localizados ou que se localizam". A segunda consiste em "instituí-lo como portador ou produtor de um sentido específico". E a terceira forma de afirmação do local é a que "faz dele um recurso total e exclusivo"; ou seja, abarca todos os domínios (social, político, econômico e simbólico) e reserva esse local a um grupo predefinido de indivíduos. Ainda conforme o autor, essas três formas constituem níveis sucessivos:

Na verdade, a afirmação local se auto-alimenta. $O$ interesse local justifica cada vez mais a um maior interesse local; o sentido de uma "grande" história local absorve outras estruturas de sentido, outras histórias, com mais ou menos eficácia e rapidez. Quanto mais cresce o interesse local, tanto mais ele tem necessidade de apoiar-se num discurso do sentido e tanto mais este se torna englobante, tanto mais tende a se transformar em expressão de um recurso total e exclusivo. (BOURDIN, 2001, p. 204).

A constituição do Sítio Histórico e Patrimônio Cultural Kalunga se enquadra nas três formas sucessivas apresentadas pelo autor, uma vez que o reconhecimento teve que partir de um número de atores suficientes para representar o coletivo; ao sítio foi instituído um sentido histórico e cultural relacionado a um povo de ancestralidade africana; e, por fim, o local se tornou exclusivo para uso e ocupação das comunidades Kalunga, sob a justificativa de preservação de seus valores históricos e culturais.

Assim, como bem coloca Haesbaert (2007), as "raízes" identitárias se tornam um tipo de "capital" (simbólico), que nem sempre é uma prerrogativa dos grupos a que se referem, sendo muitas vezes uma imposição de grupos hegemônicos. Mesmo assim, o autor assume que a eficácia do poder da identidade será cada vez maior se o grupo social "naturalizar" esta identidade, tornando-a aparentemente estática.
"A referência ao território enquanto entidade material revela-se aí de particular eficácia - o "eterno retorno" da identidade sendo garantido pela partilha de um território comum" (HAESBAERT, 2007, p. 53).

\section{TITULAÇÃO COMUNITÁRIA PELA PRESER- VAÇÃO CULTURAL E O DIREITO INDIVIDU- AL TOLHIDO}

De acordo com dados obtidos no portal eletrônico do INCRA, de 15 de dezembro de 2011, as comunidades Kalunga tiveram suas terras tituladas pela Fundação Cultural Palmares em 2000 sem a desapropriação dos títulos legítimos incidentes na área. O INCRA abriu novo processo para resolver essa situação e os decretos de desapropriação relativos a essas terras foram publicados em 2009. Conforme o quadro da situação atual de desapropriação dos territórios aquilombados, o território Kalunga possui 400 imóveis identificados em uma área de 261.999,6987 hectares, com apenas 3 ações ajuizadas. Os demais processos de titulação possuem ações de desapropriação parcialmente ajuizadas, ou seja, não houve a retirada ou indenização dos ocupantes não quilombolas (proprietários e/ou posseiros).

O problema maior, porém, é outro. Essa propriedade exclusiva mencionada anteriormente deve ser colocada em questão, pois na titulação resultante do Decreto Federal 4.887/03 o título de propriedade é registrado em nome da associação da comunidade legalmente constituída e com cláusula de "impenhorabilidade, inalienabilidade e imprescritibilidade" (art.17, $\S$ único). Isso impede que os Kalunga disponham de sua terra da forma que melhor lhes convêm, pois não podem vender, trocar ou alugar. $\mathrm{O}$ que antes era feito por um livre costume comunitário, agora passa a ser feito pela força da lei: a transmissão da posse da terra de geração para geração.

De acordo com Canto e Bernardes (2007), a obrigatoriedade imposta nesta cláusula é justificada pela necessidade de manutenção de valores culturais e organizacionais do grupo, que poderiam ser diluídos caso a titulação fosse individual. Contudo, o problema que se apresenta é que, apesar de obterem o direito de propriedade da terra garantido pelo Estado, esse mesmo Estado coloca imposições que impedem os 
quilombolas de disporem plenamente de seu direito de propriedade. Assim, o Estado pode estar reconhecendo um direito e, simultaneamente, retirando outro.

Os autores ainda explicam que a regularização da terra por meio desse decreto apresenta enorme disparidade com relação à regularização fundiária pelo Estatuto da Cidade ou pela Usucapião Coletiva, que alcança os membros da sociedade em geral. É preciso considerar, contudo, que esses institutos de regramento de áreas também têm critérios que podem não contemplar as especificidades das áreas ocupadas pelas comunidades Kalunga. Por exemplo, há a necessidade de se localizarem em zona urbana e cujo município tenha em prática um Plano Diretor, no caso do Estatuto da Cidade. Já no caso da regularização por Usucapião Coletiva, um dos requisitos é a posse incontestada, o que não acontece no território Kalunga, que tem um histórico de constantes e violentas invasões de posseiros.

A insatisfação gerada por uma titulação limitada por cláusulas impeditivas do direito pleno de propriedade é observada em entrevista, na qual uma moradora faz a seguinte consideração:

O território Kalunga, eles disse que tem que ficar assim: pra pai, pra filho, pra neto, pra bisneto. [...] Num tem aquele negócio de num querer ficar ali pro outro, não. [...] Num acho que isso é vantagem, não [...]. Ocê trabalha a vida inteirinha num lugar e se você precisar sair daquele lugar, cê tem que deixar ele de mão beijada. [...] Num pode vender! [...] Segura a pessoa naquele lugar sem a pessoa tá podendo viver naquele lugar [...]. Eu acho que foi uma ideia que teve no nosso município, no nosso território, foi uma ideia assim que pra mim [gesto de negação], não gostei [...] porque a gente não tem liberdade de usar do fruto que ocê fez. [...] Se não quiser morrer antes do tempo pra cuidar da saúde, tem que largar pra lá (Moradora de Diadema, 54 anos - 04/05/2011).

Por outro lado, conforme Arruti (2009), o fato da titulação se efetuar em nome de uma associação representativa da comunidade incorpora uma perspec- tiva comunitarista ao artigo constitucional (um direito de comunidades e não de indivíduos). Além disso, à noção de "terra" dá-se a dimensão conceitual de território: a qual não se refere apenas a terra efetivamente ocupada no momento da titulação, "mas todos os espaços que fazem parte de seus usos, costumes e tradições e/ou que possuem os recursos ambientais necessários à sua manutenção e às reminiscências históricas que permitam perpetuar sua memória" (ARRUTI, 2009, p. 85).

O território Kalunga, nesse sentido, assume o sentido de território postulado por Haesbaert (2010), que é composto por três vertentes: a jurídica e política, pelo qual o espaço territorial recebe delimitações e controle com implicação de relações de poder; a econômica, porque também é produto das relações de trabalho; e a cultural, na qual o território se forma por dimensões simbólicas que resultam na apropriação de uma identidade social sobre o espaço.

\section{CONSIDERAÇÕES FINAIS}

As análises realizadas nesse artigo possibilitaram demonstrar que a comunidade Kalunga é uma organização social constituída a partir dos esforços da população dessa região em manter-se em seu território. Para garantir o direito a terra, os Kalunga recorreram a diversas estratégias de reprodução, como a apropriação de uma nova categoria identitária: a de quilombolas.

Para Chianca (2010), foram as ameaças à integridade territorial, somadas ao novo direito constitucional, que resultaram em emergências étnicas de afirmação identitária. "De comunidades negras rurais a comunidades remanescentes de quilombos, a emergência étnica nas vias do referido direito constitucional é parte de um fenômeno mais amplo, a saber, o processo de territorialização dessas comunidades" (CHIANCA, 2010, p.15).

Nesse processo, o aumento da coesão grupal contribui para fazer frente aos conflitos pela terra, que sempre giraram em torno da chegada das estradas, das grilagens, das áreas particulares sobrepostas às áreas de uso comunitário, dos projetos de aproveitamento energético dos recursos hídricos do território, da reatualização da atividade minerária, entre outros. 
O que se pretendeu problematizar não foi propriamente a emergência étnica evidenciada na comunidade Kalunga, tampouco o fato de a mesma assumir uma identidade motivada pelos benefícios que esse autoreconhecimento pode gerar. $\mathrm{O}$ cerne do problema está na manipulação da identidade Kalunga, cujo teor essencialista não apenas interfere na dinâmica interna da população local, como deixa à margem problemas muito maiores que a coloca numa condição de cidadania incompleta.

Além da inexistência do direito pleno do uso da terra, outros problemas ainda persistem nas comunidades, como deficiências no sistema educacional, nos serviços de saúde e de infra-estrutura social básica (energia elétrica, transporte, estradas, comunicações, saneamento básico); péssimas condições de moradia; falta de documentação pessoal; dificuldades na obtenção de aposentadoria; êxodo da população para as cidades; pouco aproveitamento das matérias-primas locais e dos recursos naturais, produtividade limitada das atividades econômicas e falta de acesso à economia de mercado, deixando muitas famílias abaixo do nível da pobreza; subnutrição; discriminação étnica; e uma situação fundiária não regularizada.

Almeida (2005) faz um estudo que demonstra como as transformações que estão em curso no Cerrado geraram processos nos quais certos territórios foram sendo gradativamente reclusos. Se apoiando no que postulou Haesbaert (2004), para o qual os grupos socialmente excluídos ou segregados, impedidos de obterem o controle efetivo sobre seus territórios encontram-se num processo de precarização territorial, a autora inclui os Kalunga como grupos, entre outros, que foram hegemonizadas e tiveram seus lugares refuncionalizados.

Arruti (2009) observa como os quilombolas estão sendo incorporados nas demais políticas públicas (como a de educação e saúde) de uma forma apenas redistributivista. Ou seja, uma forma que não atende às reais demandas desses grupos diferenciados não apenas por seu caráter étnico, mas pelos processos de segregação que historicamente os excluíram da educação formal, da participação da esfera de tomadas de decisão e da sociabilidade municipal. Atualmente, há um intenso debate sobre a implementação de políticas públicas voltadas para comunidades qui- lombolas, como o Programa Brasil Quilombola do Governo Federal, constante do Plano Plurianual - PPA 2004/2007, anunciado enfaticamente com excelentes previsões orçamentárias. Entretanto, os ministérios não cumprem tal orçamento, executando parcelas mínimas das atividades previstas.

Acredita-se que o benefício de programas e políticas sociais não deve depender de nomeações nem ter como requisito a construção de uma identidade, pois esta é um fator totalmente conversível, de forma que o que hoje é negado, amanhã pode ser afirmado de acordo com a conveniência dos grupos.

Entende-se que a constituição do Sítio Histórico Cultural Kalunga criou uma identidade para os Kalunga, impondo-lhes uma imagem que os identifica como remanescentes de quilombos, quando a necessidade maior não era reconhecimento externo. Mas foi por esse reconhecimento externo que os Kalunga puderam se apropriar de ações e políticas que influenciam na sua sobrevivência. Esse processo iniciou-se com o Projeto Kalunga Povo da Terra e a lei estadual n¹1.409-91 e a "busca dos direitos" se estende por meio de diálogos entre a Secretaria Especial de Políticas de Promoção da Igualdade Racial (SEPPIR), FCP, INCRA e Ministério do Desenvolvimento Agrário (MDA).

Interessa nessas considerações finais destacar a necessidade de repensar as políticas que priorizam a preservação cultural para os grupos remanescentes de quilombos. Afinal, por quem isto é tido como primordial e necessário e quais os interesses advindos? Se a afirmação identitária é o primeiro passo para o reconhecimento oficial e destinação de todas essas políticas públicas, por que esses problemas continuam tão latentes?

Enfim, em concordância com o que defende Arruti (2009), o desenvolvimento dessas comunidades aponta para a passagem de uma perspectiva voltada exclusivamente para o reconhecimento cultural para outra que integra o objetivo da redistribuição ao reconhecimento de determinadas particularidades de natureza social e cultural.

Os conflitos fundiários pelos quais passaram os Kalunga definiram a apropriação de uma identidade quilombola e desencadearam o processo de territorialização dessas comunidades. Este último pode significar uma atitude emancipatória e o início para o caminho da cidadania ativa, que luta também por outros direitos. 


\section{REFERÊNCIAS}

ALMEIDA, Maria Geralda de. A captura do Cerrado e a precarização de territórios: um olhar sobre sujeitos excluídos. In: ALMEIDA, Maria Geralda de (Org.). Tantos Cerrados: múltiplas abordagens sobre a biogeodiversidade e singularidade sociocultural. Goiânia: Ed. Vieira, 2005. p. 321-47.

ALMEIDA, Maria Geralda de. Dilemas territoriais e identitários em sítios patrimonializados: os Kalunga de Goiás. In: PELÁ, Márcia; CASTILHO, Denis. Cerrados: perspectivas e olhares. Goiânia: Ed. Vieira, 2010.

ARAÚJO, Alexandre. M.; NAZARENO, Elias. Remanescentes de quilombo: o processo de etnogênese numa comunidade afro-descendente de Goiás. Revista Brasileira do Caribe (No prelo), aceito em 2011.

ARRUTI, José Maurício. Políticas públicas para quilombos: terra, saúde e educação. In: PAULA, M.; HERINGER, R. (Orgs.). Caminhos convergentes: Estado e Sociedade na superação das desigualdades raciais no Brasil. Rio de Janeiro: Fundação Heinrich Boll, ActionAid, 2009. p. 75-110.

ARRUTI, José Maurício. Mocambo: Antropologia e História do processo de formação quilombola. Bauru, SP. Edusc, 2006.

ASSOCIAÇÃO BRASILEIRA DE ANTROPOLOGIA. Documento do grupo de trabalho sobre comunidades negras rurais. Rio de Janeiro, 1994.

BHABHA, Homi. O local da cultura. Belo Horizonte: Ed. UFMG, 1998.

BAIOCCHI, Mari de Nasaré. Kalunga: Povo da Terra. Goiânia: Ed. Da UFG, 2006.

BOURDIN, Alain. A questão local. Trad. Orlando dos Santos Reis. Rio de Janeiro: DP\&A, 2001.

CANTO, Adéli C. do; BERNARDES, Marcio de S. Territórios Quilombolas: por uma análise crítica da regularização fundiária das terras de preto no Brasil. Revista Jurídica da Fadisma, Santa Maria, v. 2, n. 1, 2007. p. 1-16.
CHIANCA, Priscila Pessoa. Nas vias do reconhecimento: emergência étnica e territorialização Kalunga. 2010. 136 fl. Dissertação (de Mestrado em Desenvolvimento Sustentável) - Centro de Desenvolvimento Sustentável, Universidade de Brasília, Brasília, 2010.

FUNDAÇÃO CULTURAL PALMARES. Fundação cultural Palmares (sítio na internet). Disponível em: $<$ http://www.palmares.gov.br/>. Acesso em 12 jun. 2011.

HAESBAERT, Rogério. Precarização, Reclusão e "Exclusão" Territorial. Revista Terra Livre, Goiânia: AGB, v. 2, n. 23, ano 20, 2004, p. 35-52.

HAESBAERT, Rogério. Identidades territoriais: entre a multiterritorialidade e a reclusão territorial (ou: do hibridismo cultural à essencialização das identidades). In: ARAÚJO, F.G.B.; HAESBAERT, R. (Orgs.). Identidades e territórios: questões e olhares contemporâneos. Rio de Janeiro: Access, 2007, p. 33-56.

HAESBAERT, Rogério. O mito da desterritorialização: do "fim dos territórios" à multiterritorialidade. 5. ed. Rio de Janeiro: Bertrand Brasil, 2010.

INSTITUTO NACIONAL DE COLONIZAÇÃO E REFORMA AGRÁRIA. Quadro atual de politica de regularização de territórios quilombolas no INCRA. Disponível em: $<$ http://www.incra.gov.br/index.php/estrutura-fundiaria/quilombolas $>$. Acesso em 28 jun. 2012.

MARINHO, Thaís Alves. Identidade e Territorialidade entre os Kalunga do Vão do Moleque. 2008. 208 fl. Dissertação (de Mestrado em Sociologia) - Faculdade de Ciências Humanas e Filosofia, Universidade Federal de Goiás, Goiânia, 2008.

PROGRAMA BRASIL QUILOMBOLA. Perfil das Comunidades Quilombolas: Alcântara, Ivapurunduva e Kalunga - Instrumento Facilitador para o Agenciamento de Políticas Públicas Secretaria Especial de Políticas de Promoção da Igualdade Racial - SEPPIR/Governo Federal - Programa Brasil Quilombola. Brasília, 2004. 